\title{
Other Cytogenetic Analysis Abnormality Type
}

National Cancer Institute

\section{Source}

National Cancer Institute. Other Cytogenetic Analysis Abnormality Type. NCI Thesaurus.

Code C160761.

A result that is other than those presented in the form. 